\title{
Alternative and traditional medicine approaches for substance abuse programs: a shamanic perspective
}

\author{
Michael Winkelman* \\ Department of Anthropology, Arizona State University, PO Box 872402, Tempe, AZ 85287-2402, USA
}

Received 1 February 2001; accepted 1 June 2001

\begin{abstract}
Analysis of the relationship of altered states of consciousness (ASC) to culture and human psychobiology provides guidance for new approaches for addressing substance abuse and dependence. While Western cultures have a long history of repressing ASC, cross-cultural research illustrates the ubiquitous human drive to alter consciousness and the near universality of institutionalized healing practices based on ASC. These may reflect adaptive mechanisms that do not operate in contemporary societies as they did in the human past. Effectiveness of ASC procedures in treating substance dependence is found in ethnomedical treatments of addiction, the addiction literature, Alcoholics Anonymous, and the physiological effects of shamanistic practices. A review of shamanic therapeutic mechanisms illustrates their applicability to addressing the psychodynamics of drug addiction. The utility of natural ASC practices to reduce substance dependence problems is illustrated by clinical research on the treatment of drug dependence through the use of meditative practice and models of their psychobiological dynamics. Shamanistic practices induce the relaxation response, enhance theta-wave production, and stimulate endogenous opioid and serotonergic mechanisms and their mood elevating effects. Directions of a shamanic based ASC therapy for drug dependence are suggested. (C) 2001 Elsevier Science B.V. All rights reserved.
\end{abstract}

Keywords: Traditional medicine; Substance abuse programs; Shamanic perspective; Altered states of consciousness

\section{Introduction: culture, consciousness and addiction}

Substance abuse and its consequences produce health and social problems, but the current practices for management of addic-

\footnotetext{
* Tel.: + 1-480-965-6215; fax: + 1-480-965-7671.

E-mail address: michael.winkleman@asu.edu (M. Winkelman).
}

tion are inadequate. Failure to effectively address the problems of the addicted population produces major political and financial consequences for the broader society (Amaro, 1999). Treatment programs are inadequate for many reasons-limited availability and funding, a lack of knowledge and awareness of alternatives, and the failure to develop adequate public policy. This lack of treatment programs also reflects cultural impediments to the practice of scientific 
medicine and preventive health. These cultural barriers derive from historical attitudes that have shaped societal views of consciousness altering substances and policy perspectives on management of drug problems (McPeake et al., 1991; Jung, 2001, Fox, 1999). This results in ineffective approaches focused upon drug supply interdiction and persecution of users rather than provision of adequate prevention and rehabilitation services.

Current practices of incarcerating drug offenders are ineffective as rehabilitation programs. Most people incarcerated for substance abuse related crimes are returned to prison as a consequence of repeated drug abuse (Bearman et al., 1997). Treatment is available to only about, one third of the estimated 5.3 million Americans who have severe needs for substance abuse treatment (Amaro, 1999). Most treatment programs have limited annual and lifetime coverage, relapse penalties which make them ineffective and underutilized, and high levels of recidivism. Existing rehabilitation programs may be no more successful than the spontaneous remission or natural self-recovery occurring in the untreated population (Alexander et al., 1994; Miller, 1998b; Sobell et al., 2000; Cunningham et al., 2000). New policy and program directions for management of drug dependence and its consequences need to be developed. These can be derived from a recognition of cultural biases impeding the use of scientific knowledge regarding substance abuse prevention and the development of cross-cultural perspectives about alternative healing resources for addressing these problems.

Consideration of alternative and complementary healing approaches to substance abuse rehabilitation is supported by the limited effectiveness of contemporary substance abuse prevention and treatment programs, and the increasing openness towards traditional healing practices. This new openness is exemplified in the World Health Organization (1978) declaration at the International Conference on Primary Health Care in Alma Ata, where the "Health for All by the Year 2000 " program was initiated to incorporate traditional healers into primary health care. Acceptance of alternative approaches was institutionalized in the US Government's National Institute of Health's National Center for Complementary and Alternative Medicine.

Consideration of alternative approaches to drug abuse rehabilitation has, until recently, been largely limited to suggestions or insights (e.g. Lex and Schor, 1977; Blum and Tilton, 1981; McPeake et al., 1991; Rioux, 1996) rather than systematic approaches. Nonetheless, a growing body of evidence supports consideration of these therapies as means for addressing substance abuse prevention and rehabilitation. This includes: the relevance of acupuncture for treatment of opiate based addictions (e.g. Brumbrough, 1993; Riet et al., 1990; Avants et al., 2000) and the use of Transcendental Meditation practices as successful means of treating addictions (see O'Connell and Alexander, 1994; Alexander et al., 1994); and cross-cultural reviews of ethnomedical approaches to addiction treatment (Jilek, 1994; Heggenhougen, 1997; Singer and Borrego, 1984).

The reputedly most successful substance abuse rehabilitation program is Alcoholics Anonymous (1976, 1987), a non-medical therapy that advocates meditation, a change in consciousness, and spiritual awakening as fundamental to achieving and maintaining sobriety. Shamanic practices, the most ancient of ASC spiritual healing approaches, may also have potential effectiveness in eliciting psychobiological (opioid and serotonergic) mechanisms (Winkelman, 2000), and 
addressing psychosocial and emotional dynamics of drug addiction (Rioux, 1996). Shamanistic practices induce a relaxation response, provoke integrative theta wave discharges, stimulate endogenous opioid production, and enhance serotonergic mechanisms and their mood elevating effects. The relationship of drug addiction to human psychobiological needs for experiencing alterations of consciousness also suggest the potential utility of ASC for addressing drug addiction.

This paper reviews evidence supporting the use of alternative healing approaches based in ASC as adjuncts to substance abuse programs. It reviews the rationale for addressing addiction in the context of ASC (McPeake et al., 1991; Metzner, 1994; Miller, 1998a); presents principal aspects of the application of ethnomedical healing practices to substance abuse rehabilitation derived from cross-cultural reviews (Jilek, 1994; Heggenhougen, 1997); assesses some studies and meta-analyses that provided evidence of the effectiveness of an ASC (transcendental meditation) in substance abuse rehabilitation (Gelderloos et al., 1991; Alexander et al., 1994; O'Connell and Alexander, 1994; Walton and Levitsky, 1994); and summarizes material that illustrates the potential of shamanic therapies for addressing substance abuse (Lex and Schor, 1977; Miller, 1998a; Rioux, 1996; Smith, 1994, 2000; Winkelman, 2000).

\section{Psychobiology, culture and the alteration of consciousness}

Drug use and addiction are obviously associated with the alteration of consciousness; however, substance abuse problems have not been widely analyzed from the perspectives of consciousness theory or cross-cultural patterns of the use of ASC. Weil (1972) and
Siegel $(1984,1990)$ have proposed an innate drive to seek ASC. This perspective is substantiated by Mandel's (1980) psychobiological model of 'transcendent states' that considers diverse ASC to share common psychobiological mechanisms (c.f. Winkelman, 1986, 1992, 1997, 2000). Nearly all societies have institutionalized ritual group procedures for altering consciousness (Bourguignon, 1968, 1973; Winkelman, 1986, 1992). This near-universal distribution of ASC for healing reflects a biologically based mode of integrative consciousness (Winkelman, 2000) and indicates that all cultures need to make some adaptation to these needs.

Cultures differ, however, in how they relate institutionally and personally to the experiences and potentials of ASC (Laughlin et al., 1992). They represent the differences in cultural approaches to ASC as ranging from 'monophasic' cultures which institutionally value only waking consciousness through 'polyphasic void' cultures that value and actively encourage exploration of different phases of consciousness. Widespread Western biases against ASCs, manifested in efforts to marginalize, persecute or pathologize them (Noll, 1983; Grinspoon and Bakalar, 1979; Harner, 1973), contrast with most cultures' group rituals to enhance access to ASC. These cultural biases inhibit recognition of the factors that contribute to drug abuse and prevention (Amaro, 1999; Jung, 2001).

Even with cultural repression of ASCs, they are still sought because they reflect systemic natural neurophysiological processes involved with psychological integration or holotrophic responses (Winkelman, 2000; c.f., Grof, 1980, 1992). Although cultures differ in their evaluation of and support of ASCs, people in all cultures seek ASC experiences because they reflect biologically based structures of consciousness for producing holistic growth and integrative consciousness. This 
near-universality of institutionalization of ASC induction practices reflects human psychobiological needs. An evolutionary perspective on substance abuse (Smith, 1999; Wilshire, 1998) suggests that humans have evolved addictive potentials for adaptive reasons or as an evolutionary by-product. These evolutionary mechanisms may be explained by the dopamine hypothesis (Smith, 1999) that postulates their role in producing feelings of well-being. In any case, the conditions that led to these adaptations are different that those faced in modern societies.

Since contemporary Indo-European societies lack legitimate institutionalized procedures for accessing ASCs, they tend to be sought and utilized in deleterious and self-destructive patterns - alcoholism, tobacco abuse and illicit substance dependence. Since ASC reflect underlying psychobiological structures and innate needs, when societies fail to provide legitimate procedures for accessing these conditions, they are sought through other means. Incorporation of practices to induce ASC through non-drug means could be useful as both a prophylactic against drug abuse, as well as a potential treatment for addiction. This potential of shamanic ASC as therapies for substance abuse rehabilitation is illustrated in the following review of: material from the addiction field regarding the applicability of ASC and shamanic practices to substance dependence; cross-cultural literature on traditional healing approaches to addiction; and the psychodynamic and psychobiological effects of shamanic practices and ASCs.

\section{Addiction and ASC}

There have been no systematic assessments of the relationship of ASC to addiction, but a number of writers have suggested relation- ships among substance dependence, ASC, ritual and spirituality (e.g. Lex and Schor, 1977; Blum and Tilton, 1981; McPeake et al., 1991; Metzner, 1994; Miller, 1998a; Smith, 1994; Rioux, 1996). McPeake et al. (1991) point out that substance abuse rehabilitation treatment programs have failed to incorporate the knowledge provided by a vast body of literature indicating the important health benefits of altered states of consciousness. They suggest a primary reason for relapse is failure of treatment programs to address basic needs for achieving ASC and providing alternative methods for achieving those ASCs. Metzner (1994) analyses addictive experiences in terms of ASC, characterizing addictions as a contracted state of consciousness, in contrast with the expansive states of consciousness of the transcendent mystical states and ecstasy. Addicts engage in a normal human motive to achieve altered states of consciousness, but in self-destructive ways because they are not provided the opportunity to learn "constructive alternative methods for experiencing non-ordinary consciousness" (McPeake et al., 1991, p. 76). The importance of an alteration of consciousness in substance abuse recovery is emphasized in the AA recovery process, which calls for "a new state of consciousness and being" (Alcoholics Anonymous, 1987, p., 106) designed to replace the self-destructive pursuit of alcohol- induced altered states with a positive life enhancing approach.

Standard approaches to addressing substance dependence have failed to consider the role of ASC in human nature or drug dependence. "[I]t is rare to find substance dependence explained by the desire to experience more sought-after states... [the] 'high' so often described by the drug-dependent person as the state being sought" (McPeake et al., 1991, p. 76). Metzner compares Eastern and Western approaches to addiction recovery, contrasting the western tradition exemplified 
in Dante's classic "Descent into Hell" with an Asian model focused on meditative practices that lead to transcendence and expanded consciousness. This perspective is important since research indicates that central characteristics of those involved in drug use and abuse are sensation seekers in pursuit of new experiences and an expanded awareness.

The cultural perceptions of ASC activities as socially disapproved results in a meansend confusion and the rejection of the legitimate and valuable aspects of the alteration of consciousness for substance abuse rehabilitation. "Despite the rich literature on ASCs in psychology and spiritual writing, and despite the fact that AA clearly points its members toward an ASC, reviewing the published literature on rehabilitation treatment or surveying current rehabilitation treatment programming reveals a paucity of writing or treatment programming that clearly integrates ASCs with recovery" (McPeake et al., 1991, 78). They point to the lack of understanding of ASCs among treatment professionals, as a consequence of negative social attitudes towards ASCs and the lack of professional training.

McPeake et al. (1991) propose an altered states of consciousness therapy approach to substance abuse as a natural complement to the AA Twelve-Step recovery program (Alcoholics Anonymous, 1976, 1987). ASCs can enhance recovery by inducing 'positive mental attitudes, goal directedness, certain types of cognition or self-talk, certain types of imagery, as well as consciousness of a power greater than self' (McPeake et al., 1991, p. 78). This ASC Therapy (ASCT) approach meets human needs to alter consciousness and provides a path for personal growth and development associated with transcendental needs. Such an approach can help address substance abusers genetic or other predisposition to seek altered states and allow them to move beyond the developmentally fixated stage of drug dependence. Training in inducing ASCs can enhance the spiritual awakening considered essential to recovery in AA.

An ASCT program should provide both patient and staff education, as well as a variety of opportunities for non-drug induced alterations of consciousness. These would include: physical activities, including extensive exercise which could induce the opiate mediated "runners high;" activities in nature which can provide opportunities for "natural high" experiences; relaxation training based on progressive relaxation; yogic techniques and the use of vivid imagery; cognitive therapies in art and other forms of aesthetic experience; and meditation and prayer, including Eastern meditative techniques, mantras, biofeedback, dance, music and other natural methods of inducing ASC.

McPeake et al. (1991) recognize the lack of controlled outcome studies for evaluating the effectiveness of ASC therapies in substance abuse rehabilitation. They report anecdotal information indicating the efficacy of this approach. Substance abuse clients strongly endorse these ASCT principals; therapists already utilize many of these modalities as supportive aspects of therapy; and the ASCT approach helps people recontextualize the religious aspect of the Twelve-Step program in ways that are easier to understand the objectives. The utility of an ASCT approach is also validated by cross-cultural reviews of the traditional ethnomedical approaches to addictions.

\section{Traditional ethnomedical treatments of addiction}

Heggenhougen (1997) and Jilek (1994) (c.f. Singer and Borrego, 1984) review a range of nonwestern traditional indigenous ap- 
proaches to substance abuse treatment in order to determine general patterns of these healing processes and their advantages and disadvantages. Their considerations of nonWestern therapies for drug addiction are placed in the context of WHO programs of 'Health for All' through establishing the scientific basis for traditional healing practices and incorporating them into health care systems. Their reviews of the utilization of traditional medicinal practices in the treatment of addiction reveals a lack of formal clinical evaluation, but widespread evidence that they are likely effective.

Traditional treatments of addicts in Malaysia with Chinese medicine and in Thailand with Buddhist approaches typically include the use of plant medicines during the detoxification phase and when the craving for drugs returns; these often induce extensive vomiting; analysis of samples suggest that they contain indole alkaloids (Heggenhougen, 1997). These healing processes also employ various procedures for internal and external purification (e.g. purging), and a public admission of errors and a commitment to a new path. The induction of ASC through culturally congenial processes helps intensify the effects of suggestion and facilitates affective release and psychodramatic abreaction. Treatment includes rhythmic repetitive readings, cleansing baths, and massages; and the use of group ritual providing a support system for developing a positive identity and coping skills. These rituals use cultural images and symbols that address the affective level, facilitated by a collective therapy group in which participation helps foster a relational therapeutic approach that facilitates the client's social reintegration.

Similar features found in other ethnomedical approaches to the treatment of drug addiction include addressing physical, social, psychological and spiritual levels. They typi- cally include: practices for detoxification, including the use of traditional plant remedies; a process of transformation and revitalization involving a 'death and rebirth ritual' producing a positive self-image; coping mechanisms and social support that helps maintain abstinence; a means of achieving 'highs' without drugs; addressing psychosocial aspects of addiction (e.g., negative self-perception, alienation and a sense of anomie or meaninglessness that lead to addiction); and supportive socio-cultural factors by creating a therapeutic focus at the level of community with support-groups and regular ritual interaction (Heggenhougen, 1997).

In contrast to hostile Western attitudes toward most drug-induced ASC (alcohol and nicotine being exceptions), many cultures have a positive view of ASC induced by plant medicines or 'sacred plants' (e.g. see Dobkin de Rios, 1984; Schultes and Hofmann, 1979; Winkelman, 1996). The use of indole alkaloids for treatment of substance dependence is exemplified by the Native American Church or Peyote Religion. The Peyote ritual combines a variety of effective psychotherapeutic modalities along with psychotropic drugs (see Aberle, 1966; Wiedman, 1990). Other cultural traditions and addict groups have utilized similar chemical substances (see Heggenhougen, 1997; Jilek, 1994; Andritzky, 1989; Sanchez-Ramos and Mash, 1996; Mabit et al., 1996). Although the psychotherapeutic effectiveness of these substance have undergone limited assessment (e.g. see Bliss, 1988; Yensen, 1985, 1996; Passie, 1997), they have been largely banned from human research and psychotherapeutic practice for over 30 years. The political climate makes them unlikely candidates as therapeutic applications for addictions, although they are likely effective for a range of conditions (Winkelman, 2001). However, non-drug means of achieving these ASC have equiva- 
lent neurological and psychodynamic properties (Mandell, 1980, Winkelman, 1996, 1992, 1997, 2000; Grof, 1980, 1992) and may also be as effective in addressing addictions. 'Most alternative therapies engage addicts in a process of transformation and revitalization... through which the addicts realize that different and more profound 'highs' can be achieved without reliance on drugs' (Heggenhougen, 1997, p. 91).

\section{Psychobiological aspects of shamanic healing}

Cross-cultural patterns of shamanic ritual practices and beliefs reflect psychobiological structures of the brain (Winkelman, 2000). This psychobiological perspective is proposed by researchers in 'biogenetic structuralism' (e.g. Laughlin et al., 1992; d'Aquili and Newberg, 1999) as reflecting innate representational structures of self. The shamanic paradigm may be particularly appropriate for addressing addictive psychodynamics because of its basis in innate modules that represent self, other and cognitive-emotional structures and processes.

Shamanic practices also have potential utility as treatments for drug abuse because of their psychophysiological effects (Winkelman, 2000). Shamanic ASC reflect the many different procedures that induce common physiological changes involving 'transcendence' (Mandell, 1980) or an integrative mode of consciousness (Winkelman, 2000). Shamanistic ASC evoke the basic relaxation response characterized by a generalized activation of the parasympathetic nervous system, producing a regenerative and recuperative state. Shamanic ASC induce the parasympathetic response, low frequency brain waves, interhemispheric synchronization and limbic-frontal integration. Mandell (1980) proposes the common physiological mechanisms underlying diverse ASCs ('transcendent states') are based in serotonergic mechanisms involving the temporal lobe. This results in increases in high voltage slow wave EEG activity (alpha, theta, and delta, especially 3-6 cps) provoked by hypersynchronous discharges across the hippocampal-septal-reticular-raphe circuit. These spread from the brain stem-limbic circuits to the frontal lobes, producing pleasurable sensations and feelings of well-being.

\section{Opioid mechanisms}

Winkelman $(1992,2000)$ reviews the physiological aspects of many different shamanic ASC practices, illustrating their common effects across many different procedures, and their inherent therapeutic effects related to addiction involving stress reduction and opioid elicitation. Physical mechanisms for opioid elicitation in shamanistic healing include extensive drumming, dancing and clapping; repetitive physical activity; temperature extremes (e.g. sweat lodges); stressors such as fasting, flagellation, and self-inflicted wounds; and nighttime activities when endogenous opioids are naturally highest (see Bodnar, 1990; Kiefel et al., 1989; Mougin et al., 1987; Rahkila et al., 1987; Sforzo, 1989; Thoren et al., 1990; c.f. Prince, 1982 and Ethos, 10, \# 4, 1982). Shamanistic healing practices involve rituals that enhance social integration, strengthen group identity, and promote interpersonal and social bonding at physiological and psychosocial levels. A literature review (Frecska and Kulcsar, 1989) indicates that these shamanic community activities affect opioid-attachment interactions, utilizing the innate drive for affiliation to evoke opioid release. Ceremonial opioid release is based in emotionally charged cultural symbols that are cross-conditioned with endocrine systems during early socialization, linking somatic re- 
sponses to symbol systems. This association provides a basis for ritual elicitation of the opioid system through shamanic rituals.

Lex and Schor (1977) review cross-cultural data on ritual and natural forms of ASC induction through manipulating the nervous system (e.g. repetitive stimuli, drumming and other auditory driving, music and chanting, dancing, etc.) that suggests they induce alterations in the brain similar to those produced by drugs. Opiate receptor locations in the brain illuminate functions of ritual ASC. The opiate receptors are most highly concentrated in the limbic system and mid brain structures primarily responsible for motivational and affective behaviors, and directly connected to the corpus striatum. These brain structures mediate 'species typical behaviors' which are compulsive, ritualistic and repetitious and emotionally charged reactions. Ritual and emotion have an intimate relationship. The numerous ritual mechanisms for eliciting the activity of the opiate system, and the parallels between ritual and opiate effects on behavior, suggests ritual affects opiate receptors, and can therefore provide a means of addressing addictions.

\section{Transcendental meditation as treatment of addiction}

The potential for shamanic ASC to therapeutically address addictions is supported by clinical research, meta-analyses, and applied assessments on the utility of meditation practices as part of substance abuse rehabilitation programs (e.g. see O'Connell and Alexander, 1994). The overall physiological dynamics of meditation ASC are the same as those associated with other ASC (Mandell 1980; Winkelman, 1992, 2000) suggesting that the effectiveness of meditation in drug rehabilitation would also derive from other shamanic ASC.
Several researchers (Gelderloos et al., 1991; O'Connell, 1991; Alexander et al., 1994) have provided reviews and meta-analyses of the benefits of transcendental meditation (TM) in treating substance abuse. TM influences both psychological factors underlying addictive behaviors and the disposing physiological processes involved in maintaining addiction (Walton and Levitsky, 1994). TM addresses psychological factors contributing to addiction by promoting well-being, providing gratifying experiences and enhancing contact with the deeper levels of mind and emotions. TM also addresses psychophysiological dispositions associated with anxiety, tension and stress and imbalance in serotonergic mechanisms. TM holistically strengthens many levels of prevention of substance dependence through the inherently pleasant affective experiences and the production of progressive relaxation, reductions in physiological arousal and psychological stress, and enhancing restful alertness. TM provides relief for substance abusers as 'a natural way to achieve the experiences substance users are looking for' (Gelderloos et al., 1991, p. 317). TM has the ability to reduce negative emotions associated with addiction (depression, anxiety, anger), promote positive moods and emotions, and increase feelings of happiness and wellbeing. TM addresses the multiple levels of the addictive processes: the cognitive, emotional and psychodynamic aspects; the spiritual dimension associated with core values and a dependence upon a 'higher power;' and the social environment, particularly the proximal social relations directly impacting substance abuse.

Alexander et al.'s (1994) meta-analysis of, 19 retrospective surveys, cross-sectional studies and longitudinal studies utilizing TM for the treatment and prevention of substance abuse found an effect size between the 0.5 medium treatment effects and 0.8 large treat- 
ment effects. Some of the better designed studies using addict populations had treatment effect sizes exceeding, 1. They found TM to have substantially larger effect sizes than other drug prevention programs, and concluded the TM treatment effect was not due to nonspecific aspects (e.g. attention, expectancy, social support, motivation). Their meta analysis of TM studies also found a dose response relationship, with the more regular TM practitioners having higher effect size averages.

\section{A neuroendocrine model of meditation effects}

Walton and Levitsky (1994) outline a neuroendocrine model for the mechanisms through which $\mathrm{TM}$ produces reductions in drug use and addiction. The ability of TM to reduce stress and enhance serotonin functioning addresses the physiological level of addictive behavior and the cycle of addiction - the depletion of serotonin by chronic substance abuse and the interference that it produces in homeostasis and stress responses. Neurochemical and neuroendocrine factors contributing to substance dependence are physiological imbalances caused by chronic stress. TM can intervene in stress related aspects of addiction through inducing relaxed states, lowering levels of autonomic arousal, and enhancing EEG coherence. Walton and Levitsky propose TM intervenes to break the cycle of drug dependence through actions on the locus coeruleus, increasing serotonin availability and producing an inhibitory action paralleling the effects of sedatives and opiates. TM increases serotonin levels, leading to reductions in cortisol levels, and indirectly to reduction of stimulation of limbic anger and fear centers. The serotonin enhancing effects of TM affect the activity of the hypothalamic pituitary adrenal axis and chronic stress, reversing the serotonin deple- tion effects of drug dependence and the resultant release of cortisol. '[B]ecause of serotonin's roles at multiple sites involved in successful interaction with the environment, its decreased availability may be one of the most important neurochemical components in the production of tendencies toward addiction' (Walton and Levitsky, 1994, p. 110). TM induced increases in serotonin availability mirror Mandel's (1980) model of serotonergic mechanisms for ASC ('transcendent states') in general and suggests their generic role in providing biological mechanisms for ASC to interrupt drug dependence patterns.

\section{Psychosocial dynamics of shamanic healing}

Utilization of ASC and shamanic practices in the treatment of substance dependence populations has been proposed by substance abuse counselors (Rioux, 1996; McPeake et al., 1991). Potential effectiveness of shamanic practices in addressing addiction may derive from several factors, including providing a holistic paradigm for integrating spiritual dimensions within a biopsychosocial approach. Shamanistic ASC practices have a multivariate quality that enable them to address a variety of aspects of the problems underlying substance abuse and dependence through:

1. the psychological and emotional effects of the shamanic 'journey' that meets psychodynamic needs for emotional insight, selfawareness and psychological integration (Rioux, 1996);

2. the community based support group created in shamanism that can meet social needs for an intimate community for affiliation and interpersonal support;

3. spiritual needs for contact with a power beyond ourselves (Miller, 1998a; Smith, 1994); and 
4. the physiological effects of the shamanic ASC that: induce the relaxation response and theta wave dominance (Winkelman, 2000; Mandell, 1980); stimulate the opioid system (Frecska and Kulcsar, 1989, Prince, 1982); and restore balance in the serotonergic neurotransmitter systems (Walton and Levitsky, 1994).

Shamanic practices may take a number of forms (Winkelman, 1990; Winkelman, 1992; Townsend, 1997), but share core universal aspects. These have been popularized by the anthropologist Michael Harner as 'core shamanism' (Harner, 1980/1990). The classic aspects of shamanic practice as characterized by Eliade (1964) involved ecstatic states (ASC) in interaction with the spirit world on behalf of the community. These encompass pillars of drug abuse rehabilitation - meditation and transcendence, spirituality and higher power, and community relations providing a support system. Basic aspects of a shamanic practice involve a group that engages in drumming and visionary experiences or a 'journey' in which one 'travels' to internal experiential worlds while in an ASC. Hunt (1995) has characterized these experiences as based in a presentational symbolism. These experiences reflecting symbolic structures of the non-verbal mind provide connections with self, emotions, and repressed memories and the opportunity to formulate future plans. These ASC offer a variety of opportunities to experience states of profound relaxation or excitation, insight, the release of emotions, and healing through selfintegration.

\section{Psychodynamics of shamanic healing}

Shamanism uses natural ASC that involve the brain's primary processing capacities, a presentational symbolism (Hunt, 1995) mani- fested in visual symbols, animals and spirits. These derive from biologically-based self-representation structures (Laughlin et al., 1992; Winkelman, 2000) that reflect individual and group psychodynamics. Information acquired through the vision based ASC provide material for individual and group processing. Shamanic ritual is directed towards empowering one to know oneself through entering the spirit world, to acquire allies and powers, and to heal through recovery of lost aspects of one's soul. Power animals and guardian spirits are conceptualized as 'metaphoric healing energies' (Rioux, 1996), providing an expansion of the, Twleve-Step concept of Higher Power and its healing effects. Winkelman (2000) has proposed that these animal powers reflect the innate brain processing modules operating through analogic processes. A modern perspective characterizes shamanism as learning to enhance personal power through integrating dissociated or unentrained neural structures (Laughlin et al., 1992) and entering into integrative brain states that heal unconscious aspects of the self and emotions. Shamanism provides mechanisms for developing awareness and accessing unconscious powers shaping our lives, manifested in the concepts of spirits. Shamanism elevates emotional and non-verbal dynamics, enabling us to change our character and overcome personal shortcomings by providing access to dissociated aspects of our soul and identity. ASC contribute to reduced defensiveness, acceptance of others and development of a sense of community. The group setting of shamanic practice also provides a social context for problem solving and a social group that provides a therapeutic community that can play a significant role in motivating sobriety and treatment adherence. Shamanic drumming circles also provide a social support system for spiritual awakening, leading participants 
to direct experience of spiritual powers, and naturally providing the major spiritual aspects emphasized in the AA, Twelve-Step program.

\section{Soul loss and spirituality}

A major paradigm of shamanic healing is 'soul recovery,' involving reintegration of dissociated aspects of the self. Shamanic treatment of soul loss involves a conceptualization similar to TM and AA views of addiction as resulting from a lack of spirituality. Spirituality can be seen as reflecting collective dimensions of, and the individual connectedness with, the social group. Soul loss reflects this lack of individual connection with broader units of social identity (c.f. Jilek, 1982). Since fundamental aspects of shamanic practice are concerned with establishing a connectedness with animal spirits and personal souls and allies, it can provide a means for addressing the collective soul loss and lack of spirituality thought to be a major determinant of the addictive psychodynamic. Winkelman (2000) has shown that these spiritual perceptions have a psychobiological basis, reflecting an analogic integration of innate brain modules that produce the basic structures of the brain and consciousness (Winkelman 2000). This spiritual aspect of shamanism make it a potentially important resource in addressing both psychobiological integration and incorporation of the spiritual aspects recognized as central to substance abuse rehabilitation (Miller, 1998a; Alcoholics Anonymous, 1976, 1987; Booth and Martin, 1998; Green et al., 1998).

The role of spirituality in recovery from substance abuse may reflect a protective factor provided by religious involvement and spiritual engagement (Miller, 1998a). Although the actual protective mechanisms re- main unknown, '[i]t is, in AA's understanding, spirituality that finally and reliably dries out the possessive spirit of addiction' (Miller, 1998a, p. 981). Spiritual practices may have an important role in the 'healing' of addiction by providing a sense of meaning to life often found lacking among substance abusers. Spirituality has been a significant feature of healing traditions throughout history, and many contemporary people find spirituality provides an important source of healing. Shamanism is the original and natural form of prayer and meditation which provides a direct spiritual awakening, a means for transcendence of personal consciousness, and consequently a mechanism for overcoming addiction.

Rioux (1996) illustrates how shamanic healing techniques can play a role in a holistic addiction counseling approach that integrates spiritual perspectives into a biopsychosocial approach by focusing on inner realities to produce harmony and self wholeness. Shamanic ASC can help clients achieve wholeness through transforming consciousness by providing a link between inner and outer realities, enabling inner world perspectives to operate on the outer world to produce harmony and wholeness. Important aspects of the shamanic ASC include 'focusing' of intention upon one's purpose and spending time in relaxed conditions that provide restful healing. ASC practices also free one from ego-bound emotions and provide a balance of conflicting internal energies. Work through dreaming and shamanic journeying helps achieve the sense of 'wholeness,' countering the sense of self loss at the basis of addictive dynamics, and enhancing self-esteem by providing connectedness beyond the egoic self.

Harner and Harner (2001) suggest that there are basic forms of shamanic healing that have applicability in the treatment of 
dependency on alcohol and other drugs. They specifically mention shamanic healing concepts such as depossession, soul retrieval, guardian spirit retrieval. Winkelman (2000) has characterized these healing dynamics in terms of the relationship between innate brain processing modules and the dynamics of self and other, providing mechanisms for individual integration into community life and identity.

\section{Conclusions}

A cure for addiction has yet to be achieved by medicine or pharmacology. Social environmental approaches focusing on drug prevention education have yet to curb epidemic levels of substance abuse. The current social crisis of substance abuse is coupled with the lack of institutionalized procedures for addressing innate needs for ASC and the evolutionary factors that produce drug dependence. A view of ASC as a natural human need and a part of evolved disposition suggests that addiction be addressed by providing alternative means of achieving the 'high' addicts seek. Current rehabilitation programs need to be complemented with traditional ethnomedical approaches that meet these physiological, psychological and social needs. Amaro (1999) calls for the use of all scientifically established treatment programs for demand reduction and addiction treatment. Spirituality and alternative medicine practices have been increasingly recognized as a central means for effectively addressing substance dependence, but little has been done to effectively integrate these insights.

A lack of a spiritual emphasis in the emerging biopsychosocial paradigm reflects the general lack of religious beliefs and values among US health professionals (McPeake et al., 1991). This lack of involvement and expe- rience, compounded by a lack of consideration of spiritual issues in their education, leaves health professionals poorly prepared to assess spiritual constructs. Professional and scientific responsibility demands these contributions to the addiction recovery process be assessed. 'Comprehensive addictions research should include not only biomedical, psychological and socio-cultural factors but spiritual factors of the individual as well' (Miller, 1998a, p. 979).

Shamanism reflects the primordial spiritual practices of humanity. The cross-cultural similarities in shamanism, the widespread resurgence of shamanistic practices, and their formalization in nationwide and international organizations (e.g. the core shamanism methods through the Foundation for Shamanic Studies) reflect their neurobiological basis. Shamanism provides readily available resources for developing new approaches to the management of drug addiction and rehabilitation of addicts. Shamanic practices provide a natural means of evoking the relaxation response, relieving the stress that is a principal trigger for relapse into drug use. A consequence of drug addiction is long-term changes in brain metabolism and neurotransmitter levels; shamanic practices affect natural opioid and serotonin levels depleted by drug use and can provide a natural means of stimulating the release of these natural pleasure-producing substances. Research on the preventive and treatment roles of TM in drug abuse establish the usefulness of ASC. The meditative traditions have their origins in shamanic ASC practices, and have psychophysiological effects that interrupt drug dependence and meet natural psychobiological needs for ASC and transcendent experiences.

Shamanic practices have been effectively incorporated in the healing systems of contemporary community mental health centers and appear able to meet the psychosocial and 
emotional needs of victims of violence, trauma and drug abuse (Eshowsky, 1993, 1998, 1999; Smith, 2000). The traditions that utilize these practices also provide the supportive social contexts which reduce the personal alienation and need for such substances, and address the multifactorial social and personal nature of addiction. Given the epidemic nature of drug abuse and the safe and established effects of these procedures, their development, implementation and evaluation as community treatment resources is highly desirable.

\section{References}

Aberle D. The Peyote Religion Among the Navaho. Chicago, IL: Aldine Publishers, 1966.

Alexander C, Robinson P, Rainforth M. Treating and preventing alcohol, nicotine, and drug abuse through transcendental meditation: a review and statistical meta-analysis. Alcoholism Treatment Quarterly 1994;11(1/2):13-87.

Alcoholics Anonymous, 1976. Alcoholics Anonymous. New York: AA World Services.

Alcoholics Anonymous, 1987. Twelve Steps and Twelve Traditions. New York: AA World Services.

Amaro H. 'Editorial an expensive policy: the impact of inadequate funding for substance abuse treatment'. American Journal of Public Health 1999;89(5):6579.

Andritzky W. Sociopsychotherapeutic functions of ayahuasca healing in Amazonia. Journal of Psychoactive Drugs 1989;21(1):77-89.

Avants KS, Margolin A, Holford TR, Kosten TR. A randomized control trial of auricular acupuncture for cocaine dependence. Archives of Internal Medicine 2000;160:2305-12.

Bearman D, Claydon K, Kincheloe J, Lodise C. Breaking the cycle of dependency: dual diagnosis and AFDC families. Journal of Psychoactive Drugs 1997);29(4):359-67.

Bliss K. LSD and psychotherapy. In: Contemporary Drug Problems. Winter: 1988, pp. 519-563.

Blum K, Tilton JE. Understanding the high mind. In: Meyer GG, Blum K, Cull JG, editors. Folk Medicine and Herbal Healing. Springfield, IL: Charles C Thomas, 1981:261-74.
Bodnar R. Effects of opiod peptides on peripheral stimulation and 'stress'-induced analgesia in animals. Critical Review of Neurobiology 1990;6(1):39-49.

Booth J, Martin JE. Spiritual and religious factors in substance use, dependence, and recovery. In: Koenig HG, editor. Handbook of Religion and Mental Health. San Diego: Academic Press, 1998.

Bourguignon E. Cross-Cultural Study of Dissociational States. Columbus: Ohio State University, 1968.

Bourguignon E. Introduction: a framework for the comparative study of altered states of consciousness. In: Bourguignon E, editor. Religion, Altered States of Consciousness, and Social Change. Columbus: Ohio State University Press, 1973.

Brumbrough AG. Acupuncture: new perspectives in chemical dependency treatment. Journal of Substance Abuse Treatment 1993;10:35-43.

Cunningham J, Koski-Jannes A, Toneatto T. Contemporary Drug Problems 26 Winter 2000;1999:695710.

d'Aquili EG, Newberg AB. The Mystical Mind: Probing the Biology of Religious Experience. Minneapolis, MN: Fortress Press, 1999.

Dobkin de Rios M. Hallucinogens: Cross-Cultural Perspectives. Albuquerque: Univ. New Mexico Press, 1984.

Eshowsky M. Practicing shamanism in a community health center. Shamanism 1993;5(4):4-9.

Eliade M. Shamanism: Archaic Techniques of Ecstasy. New York: Pantheon Books, 1964.

Eshowsky M. Community shamanism: youth, violence, and healing. Shamanism 1998;11(1):3-9.

Eshowsky M. Behind these walls where spirit dwells. Shamanism 1999;12(1):9-15.

Fox KJ. Ideological implications of addiction theories and treatment. Deviant Behavior: An Interdisciplinary Journal 1999;20:209-32.

Frecska E, Kulcsar Z. Social bonding in the modulation of the physiology of ritual trance. Ethos 1989;17(1):70-87.

Gelderloos P, Walton K, Orme-Johnson D, Alexander C. Effectiveness of the transcendental meditation program in preventing and treating substance misuse: a review. International Journal of the Addictions 1991;26:293-325.

Green L, Fullilove M, Fullilove R. Stories of spiritual awakening the nature of spirituality in recovery. Journal of Substance Abuse Treatment 1998;15(4):325-31.

Grinspoon L, Bakalar J. Psychedelic Drugs Reconsidered. New York: Basic Books, 1979. 
Grof S. LSD Psychotherapy. Pomona, CA: Hunter House, 1980.

Grof S. The Holotropic Mind. San Francisco: Harper Collins, 1992.

Harner M. Hallucinogens and Shamanism. New York: Oxford University Press, 1973.

Harner M. The Way of the Shaman, 3rd ed. San Francisco: Harper \& Row, 1980/1990.

Harner M, Harner S. Core practices in the shamanic treatment of illness. In: Jonas W, Levin J, editors. Textbook of Complementary and Alternative Medicine. Baltimore: Lippincott, Wilkins \& Williams, 2001.

Heggenhougen C. Reaching New Highs: Alternative Therapies for Drug Addicts. Northvale, NJ: Jason Aronson, 1997.

Hunt H. On the Nature of Consciousness. New Haven: Yale University Press, 1995.

Jilek W. Indian Healing. Surrey, BC: Hancock House, 1982.

Jilek WG. Traditional healing in the prevention and treatment of alcohol and drug abuse. Transcultural Psychiatric Research Review 1994;31:219-58.

Jung J. Psychology of Alcohol and Other Drugs: A Research Perspective. Thousand Oaks, CA: Sage Publications, 2001.

Kiefel J, Paul D, Bodnar R. Reduction of opioid and non-opioid forms of swim analgesia by 5-HT2 receptor antagonists. Brain Research 1989;500:23140.

Laughlin C, McManus J, d'Aquili E. Brain, Symbol and Experience Toward a Neurophenomenology of Consciousness. New York: Columbia University Press, 1992.

Lex B, Schor N. A proposed bioanthropological approach linking ritual and opiate addiction. Addictive Diseases 1977;3(2):287-303.

Mabit J, Giove R, Vega J. In: Winkelman M, Andritzky W, editors. Yearbook of Cross-Cultural Medicine and Psychotherapy, vol. 6. Berlin: Verlag und Vertrieb, 1996.

Mandell A. Toward a psychobiology of transcendence: God in the brain. In: Davidson D, Davidson R, editors. The Psychobiology of Consciousness. New York: Plenum, 1980.

McPeake JD, Kennedy BP, Gordon SM. Altered states of consciousness therapy - a missing component in alcohol and drug rehabilitation treatment. Journal of Substance Abuse Treatment 1991;8:75-82.

Metzner R. Addiction and transcendence as altered states of consciousness. The Journal of Transpersonal Psychology 1994;26(1):1-17.
Miller WR. Researching the spiritual dimensions of alcohol and other drug problems. Addiction 1998a;93(7):979-90.

Miller WR. Why do people change addictive behavior? Addiction 1998b;93(2):163-72.

Mougin C, Baulay A, Henriet M, Haton D, Jacquier M, Turnhill D, Berthelay S, Gaillard R. Assessment of plasma opioid peptides, beta-endorphin and metenkephalin at the end of an international nordic ski race. European Journal of Applied Physiology 1987;56(3):281-6.

Noll R. Shamanism and schizophrenia: a state-specific approach to the schizophrenia metaphor of shamanic states. American Ethnologist 1983;10(3):443-59.

O'Connell D. The use of transcendental meditation in relapse prevention counseling. Alcoholism Treatment Quarterly 1991;8(1):53-69.

O'Connell D, Alexander C, editors. Self-Recovery: Treating Addictions Using Transcendental Meditation and Maharishi Ayur-Veda. New York: Hayworth Press, 1994.

Passie T. Psycholytic and Psychodelic Therapy Research, 1931-1995: A Complete International Bibliography. Hanover, Germany: Laurentius, 1997.

Prince R. The endorphins: a review for psychological anthropologists. Ethos 1982;10(4):299-302.

Rahkila P, Hakala E, Salminen K, Laatikainen T. Response of plasma endorphins to running exercise in male and female endurance athletes. Medicine and Science in Sports and Exercise 1987;19(5):4515.

Riet GT, Kleijnen J, Knipschild P. A meta-analysis of studies into the effect of acupuncture on addiction. British Journal of General Practice 1990;40(338):379-82.

Rioux D. Shamanic healing techniques: toward holistic addiction counseling. Alcoholism Treatment Quarterly 1996;14(1):59-69.

Sanchez-Ramos JR, Mash D. In: Winkelman M, Andritzky W, editors. Yearbook of Cross-Cultural Medicine and Psychotherapy, vol. 6. Berlin: Verlag und Vertrieb, 1996.

Schultes E, Hofmann A. Plants of the Gods. New York: McGraw-Hill, 1979.

Sforzo G. Opioids and exercise: an update. Sports Medicine 1989;7(2):109-24.

Siegel R. The natural history of hallucinogens. In: Jacobs B, editor. Hallucinogens: Neurochemical, Behavioral and Clinical Perspectives. New York: Raven Press, 1984. 
Siegel R. Intoxication: Life in Pursuit of Artificial Paradise. New York: Dutton, 1990.

Singer M, Borrego M. Indigenous treatment for alcoholism: the case for Puerto Rican spiritism. Medical Anthropology 1984;8(4):246-72.

Smith DE. AA recovery and spirituality: an addiction medicine perspective. Journal of Substance Abuse Treatment 1994;11(2):111-2.

Smith D. Shamanism and addiction. Spirit Talk 2000;11:8-12.

Smith E. Evolution, substance abuse, and addiction. In: Trevathan W, Smith E, McKenna J, editors. Evolutionary Medicine. New York: Oxford, 1999:375405.

Sobell L, Ellingstad T, Sobell M. Natural; recovery from alcohol and drug problems: methodological review of the research and suggestions for future directions. Addiction 2000;95(5):749-64.

Thoren P, Floras J, Hoffmann P, Seals D. Endorphins and exercise: physiological mechanisms and clinical implications. Medicine and Science in Sports and Exercise 1990;22(4):417-28.

Townsend J. Shamanism. In: Glazier S, editor. Anthropology of Religion. Westport, CT: Greenwood Press, 1997:429-69.

Walton K, Levitsky D. A neuroendocrine mechanism for the reduction of drug use and addictions by transcendental meditation. In: O'Connell D, Alexander C, editors. Self-Recovery: Treating Addictions Using Transcendental Meditation and Maharishi Ayur-Veda. New York: Hayworth Press, 1994.

Weil A. The Natural Mind. Boston, MA: Houghton Mifflin, 1972.

Wiedman D. Big and little moon peyotism as health care delivery systems. Medical Anthropology 1990;12:371-87.

Wilshire B. Wild Hunger. Lanham, MD: Rowman and Littelfield, 1998.
Winkelman M. Trance states: a theoretical model and cross-cultural analysis. Ethos 1986;14:76-105.

Winkelman M. Shaman and Other "Magico-religious" Healers: A Cross-cultural Study of Their Origins, Nature and Social Transformations. Ethos 1990;18(3):308-52.

Winkelman M. Shamans, priests and witches. A crosscultural study of magico-religious practitioners. Anthropological Research Papers no. 44. Tempe, AZ: Arizona State University, 1992.

Winkelman M. Psychointegrator plants: their roles in human culture and health. In: Winkelman M, Andritzky W, editors. Yearbook of Cross-Cultural Medicine and Psychotherapy, vol. 6. Berlin: Verlag und Vertrieb, 1996.

Winkelman M. Altered states of consciousness and religious behavior. In: Glazier S, editor. Anthropology of Religion. Westport, CT: Greenwood Press, 1997.

Winkelman M. Shamanism The Neural Ecology of Consciousness and Healing. Westport, CT: Bergin and Garvey, 2000.

Winkelman, M. 2001. Psychointegrators: Multidisciplinary Perspectives on the Therapeutic Effects of Hallucinogens. Complementary Health Practice Review, 6(3).

World Health Organization, 1978. Alma-Ata 1978. Primary Health Care: Report of the International Conference on Primary Health Care, Alma Ata, USSR 6-12 September 1978. Geneva: WHO "Health for All" series no. 1.

Yensen R. LSD and psychotherapy. Journal of Psychoactive Drugs 1985;17(4):267-77.

Yensen R. From shamans and mystics to scientists and psychotherapists: interdisciplinary perspectives on the interaction of psychedelic drugs and human consciousness. In: Winkelman M, Andritzky W, editors. Yearbook of Cross-Cultural Medicine and Psychotherapy. Berlin: Verland und Vertrieb, 1996. 